\title{
Autoplasty by Displaced Aponeurotic Flap: Results of a New Method of Inguinal Hernias Surgical Treatment
}

Saule Tulegenovna Sapiyeva ${ }^{1 *}$, Nurkassi Tulepbergenovich Abatov², Makash Tynyshtykpaevich Aliyakparov ${ }^{3}$, Yoshihiro Noso ${ }^{4}$ Ruslan Muratovich Badyrov², Elena Sergeevna Badyrova ${ }^{2}$

${ }^{1}$ Department of Oncology and Radiology, Faculty of Medicine, Karaganda Medical University, Karagandy, Kazakhstan; ${ }^{2}$ Department of Surgical Diseases, Karaganda Medical University, Karagandy, Kazakhstan; ${ }^{3}$ Department of Oncology and Radiology, Karaganda Medical University, Karagandy, Kazakhstan; ${ }^{4}$ Department of Medical, Faculty of Business Administration, Hiroshima International University, Hiroshima, Japan

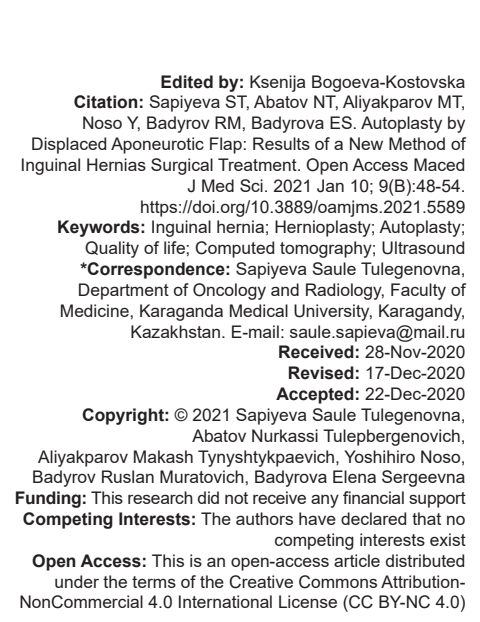

Abstract

AIM: A new surgical method of non-tension autoplasty by displaced aponeurotic flap for the treatment of uncomplicated inguinal hernias has been developed.

METHODS: Thirty patients were operated on using a new method of autoplasty; the comparison group involved 30 patients which were operated on by Liechtenstein hernioplasty using a partially absorbable mesh implant (UltraPro) The effectiveness of the methods was evaluated by clinical data, instrumental research methods (ultrasound examination, and computed tomography [CT]), and results of life quality.

RESULTS: There were no relapse cases in both groups in the early and long-term after surgery. According to ultrasound, inflammatory infiltrate was absent in the group using a new autoplasty method, subclinical seromas resolved earlier after surgery. According to data of compression elastography and CT, the formation of a denser sca in the postoperative area was registered in the comparison group with a statistically significant difference. The feeling of discomfort and pain in the study group was more pronounced in the early post-operative period in comparison with the group using a mesh implant. However, in later terms, the life quality of patients in the group using a new autoplasty method improved with a statistically significant difference.

CONCLUSION: The operation method is simple to perform, does not require the use of an endoprosthesis or extensive dissection of tissues and can be a reliable alternative and compete with prosthetic methods of hernioplasty.

\section{Introduction}

Inguinal hernia is one of the most common diseases in surgical practice because of its frequency, complexity, as well as socio-economic consequences. Worldwide, more than 20 million patients annually are operated on for inguinal hernia [1]. The incidence in the world literature is estimated in the range from $1 \%$ to $31 \%$ [2]. Despite the large number of hernioplasty methods, many issues are still not fully resolved. It is evidenced by the high rate of relapse, requiring repeated operations in $10-15 \%$ cases and longterm disability due to chronic pain occurs in 10-12\% patients [1].

Existing tensioned autoplasty methods due to their higher recurrence rate, long period of postoperative pain and recovery after surgery led to the concept of non-tension hernioplasty. For example, a method developed by the Indian surgeon Desarda is a simple surgery technique with no cases of relapse according to research [3]. Modified methods of tension autoplasty methods have been developed recently, such as the modified Bassini method, in which the relapse rate was in the range of 5.7-6.8\% [4], [5]. Nevertheless, nontension methods using a mesh implant are recognized as "the gold standard" of inguinal hernia repair. However, the endoprosthesis staying in the tissues causes a local tissue reaction of chronic inflammation in response to foreign body installation [6], [7], [8], [9], [10], [11]. Endoprosthesis causes the increased exudation and the formation of long-existing seromas with subsequent possible infection; at a longer time after surgery it causes the development of scar from the connective tissue around the implant.

All of the above redefines the search of new methods of inguinal hernioplasty, alternative to existing prosthetic variants. We can be guided by the principle of modern hernioplasty "without tension" using the autoplastic method. The use of "non-tension" autoplasty methods has a great potential in the surgical correction of inguinal hernias, as this can eliminate all the complications associated with the use of synthetic material. 
Our research team has developed a modified method for autoplasty of the inguinal canal posterior wall by displaced aponeurotic flap whose advantage is the absence of tissue tension (Intellectual Property Certificate No. 298, authors: R. M. Badyrov, N. T. Abatov).

The objective of the study was to evaluate the immediate and long-term results after applying the autoplasty method with a displaced aponeurotic flap.

\section{Materials and Methods}

Study subjects - 60 patients with diagnosed uncomplicated inguinal hernia, all the patients were males. Thirty patients were operated on using a new autoplasty method; the comparison group involved 30 patients which were operated on by Lichtenstein hernioplasty using a partially absorbable mesh implant (UltraPro). The study was conducted on the base of the Clinic of Karaganda Medical University in the period January 2017-September 2020; the operations were completed by the same surgical team. The average age of patients in the study group is 50.3 years, in the comparison group is 52.5 years. Inclusion criteria were patients at the age of 18-70 with uncomplicated inguinal hernias. Patients with relapse or restrained inguinal hernias, with severe concomitant pathology, as well as with mental illness were excluded from the study. Study approved by Local Ethics Commission and each of the study participants signed an informed consent, the selection process for the study groups was random.

\section{Surgical technique}

The repair technique of the inguinal canal posterior wall of by displaced aponeurotic flap was performed as follows: The medial sheet of the aponeurosis of the abdomen external oblique muscle was peeled off to a white line using a "blunt" method. The next step was to cut out a quadrangular aponeurotic flap $(4.0 \mathrm{~cm} \times 7.0 \mathrm{~cm}$ in size $)$ of the combined aponeurosis of the internal oblique and transverse abdominal muscles from the anterior wall of the rectus abdominis muscle vagina (Figures 1 and 2 ).

The criterion indicating that the leaf of the rectus abdominis muscle vagina is crossed through its entire thickness is the appearance of the muscle tissue of rectus abdominis muscle or fatty tissue surrounding the muscle in the wound. Formed aponeurotic flap on the feeding leg must be moved to the posterior wall of the inguinal canal under the spermatic cord. Subsequently, it was necessary to fix it by turns to the pubic tubercle, laterally - to the inguinal ligament up to the place of the

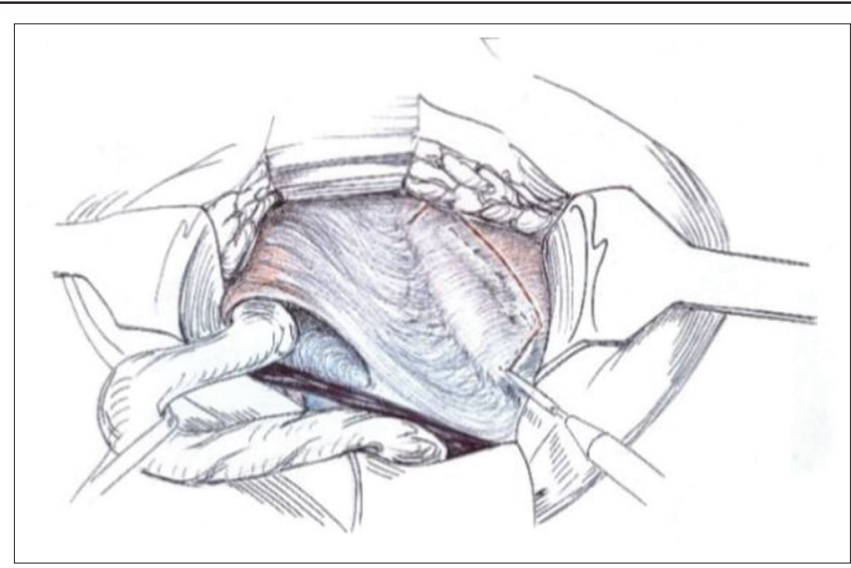

Figure 1: Extraction of the flap from the combined aponeurosis

exit of the spermatic cord from the abdominal cavity; for the spermatic cord, the lateral edge of the flap was split, retreating about $2 \mathrm{~cm}$ from the bottom to a depth of $2.5 \mathrm{~cm}$, then it was cut out to $1 \mathrm{~cm}$ in "window" diameter where the spermatic cord was moved, the flap sections were sutured to the cord; above - the aponeurotic flap was additionally fixed with interrupted sutures to the internal oblique and transverse muscles of the abdomen and the medial edge of the aponeurotic flap was sutured to the lateral edge of the rectus abdominis muscle.

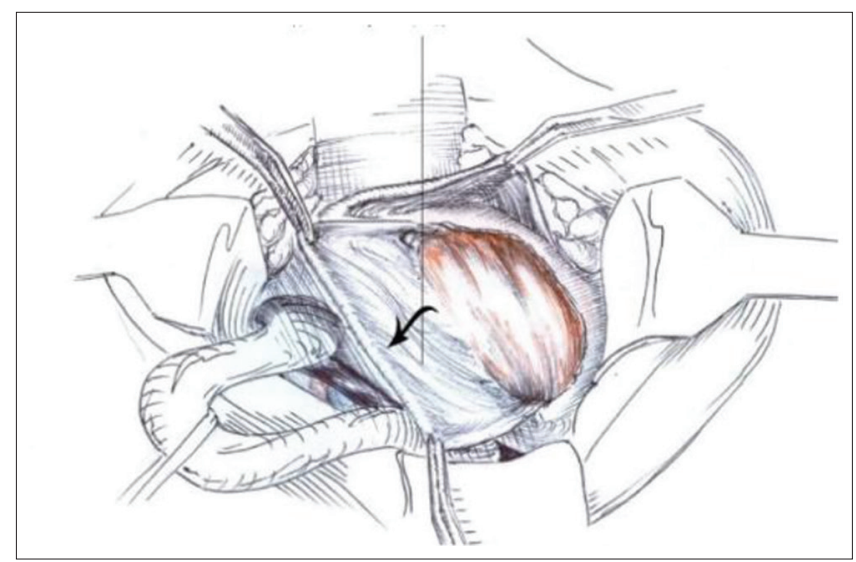

Figure 2: Flap from the anterior wall of rectus abdominis muscle vagina is highlighted and moved down for plastic surgery

A spermatic cord was placed on the newly formed posterior wall of the inguinal canal (Figure 3). Then, the integrity of the anterior wall of the inguinal canal was restored by suturing the lateral and medial leaves of the aponeurosis of the external oblique muscle of the abdomen.

\section{Methods for hernioplasty effectiveness assessing}

Clinical data were evaluated for the study of relapse and local complications (severe postoperative pain, testicular atrophy; and post-operative wound condition: Seroma formation, infection). Relapses were assessed both by physical examination of the surgeon and ultrasound using. 


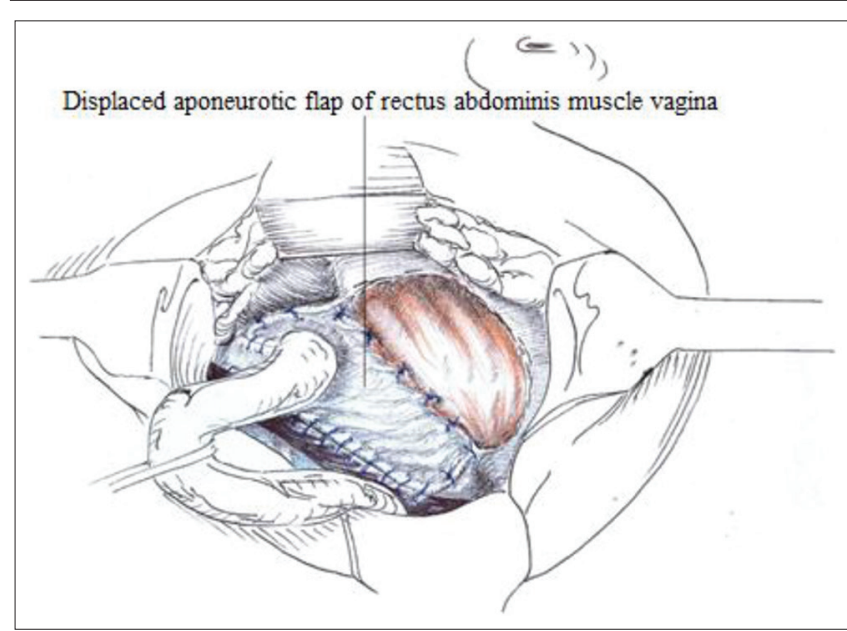

Figure 3: The inguinal triangle is closed by a displaced aponeurotic flap of rectus abdominis muscle vagina

The purpose of instrumental research methods was to objectify the control of the wound process, to predict the development of complications in the postoperative wound. An ultrasound study was conducted (in 1 week, in 1, 3, and 6 months after surgery) for the presence/absence of seroma; the presence/absence/ severity of inflammatory infiltrate. The patients were examined in supine position using a $10 \mathrm{MHz}$ linear transducer of an ultrasound device (LOGIC P9 from GE, USA). Real-time scanning was obtained in standard longitudinal and transverse sections.

Due to the impossibility of clinically confirming the fact a dense scar formation, we proposed a noninvasive, simple technique for the tissue density assessing - compression elastography of the postoperative area within 6 months after surgery. Compression of tissues with a sensor allows to a certain extent to assess their density, more accurately established using elastography [12].

Computed tomography (CT) was performed to measure the tissue density in the post-operative area and to visualize tight scars for 1 week and 6 months after surgery. Scanning was obtained in standard longitudinal and transverse sections with a 64-slice CT apparatus (Toshiba Aquilion 640).

\section{Life quality assessment methods}

The life quality of the patients was evaluated according to the questionnaire "Questionnaire for assessing the life quality of the patient after hernia repair," developed and proposed by our team (Intellectual Property Certificate No. 5645, authors: S. T. Sapiyeva, N. T. Abatov, R. M. Badyrov, Ye. S. Badyrova). This questionnaire is based on the Carolinas Comfort Scale international questionnaire and has been expanded with questions. The advantage of this questionnaire is that it consists of nine specific points that directly cover the area of the previous operation and changes in daily activity associated with

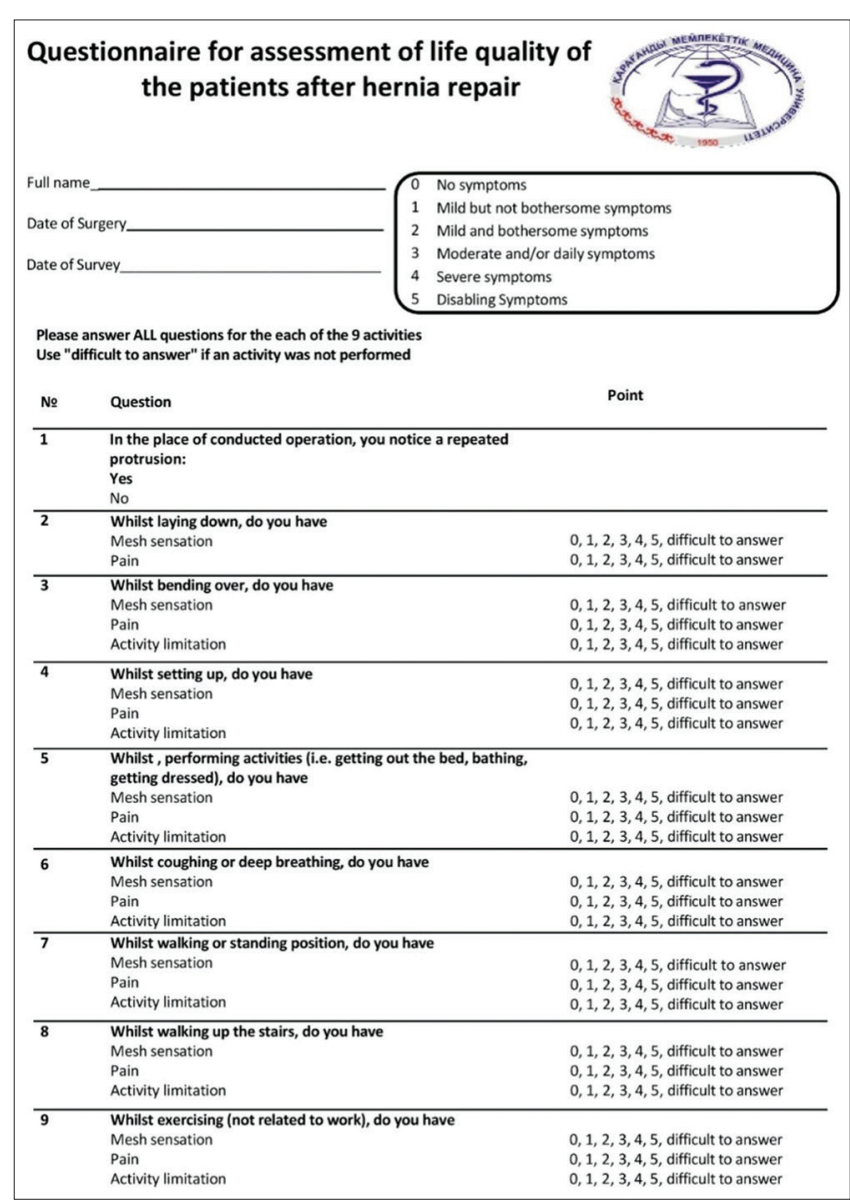

Figure 4: Questionnaire for assessment of life quality of the patients after hernia repair

it (Figure 4). The questionnaire must be filled in by patients in 1, 3, and 6 months after surgery. The main areas: Pain, limitation of activity, and the feeling of an implant. They were evaluated according to the results of answering for nine questions about everyday life on a 6-point Likert scale. Zero corresponds to the absence of symptoms, five - symptoms leading to disability. Scores from 0 to 1 (mild, but not disturbing) are classified as asymptomatic; and scores from 2 (mild and disturbing) to 5 (disturbing) are classified as symptomatic.

\section{Statistical data processing methods}

The arithmetic groups mean $(\bar{X})$ and standard deviation (SD) were calculated for all quantitative data. The significance of differences between the studied groups was determined by statistical methods using nonparametric criteria: The Mann-Whitney criterion was used to test for statistically significant differences between medians for independent groups comparing ("experiencecontrol"). The reliability of intra-group differences was determined statistically using non-parametric criteria: The Kruskal-Wallis was used to test for statistically significant differences between medians criterion for independent groups comparing. 


\section{Results}

\section{Clinical data}

\section{Assessment of local complication}

Clinically, no serious complications (such as seroma formation, infection, severe postoperative pain, and testicular atrophy) were observed for 3 years. About $70 \%$ of patients were discharged on the $6^{\text {th }}$ or $7^{\text {th }}$ days, and the average hospital stay was 6.4 days in both groups. Mild or moderate pain after surgery was registered in all the patients. All patients were able to return to their normal work within 1-2 weeks.

\section{Relapse assessment}

Clinically, there were no relapse cases in the early and long period after surgery: $0 \%$ in the main and in the comparison groups. The average follow-up in both groups was 36 months.

\section{Radiation research methods}

\section{The presence/absence of seroma}

Ultrasound scans registered aseptic fluid formations of small volumes in the form of subclinical seromas in the study group in the $1^{\text {st }}$ week after surgery, diagnosed in $50 \%$ patients, in the $1^{\text {st }}$ month $0 \%$, and in the $3^{\text {rd }}$ month $-0 \%$. Aseptic fluid formations of small volumes in the form of subclinical seromas were visualized in $50 \%$ of patients of control group within 1 week after hernioplasty, in $16.7 \%$ patients - in 1 month, and in $13.3 \%$ patients - in 3 months. The average values of the size of aseptic fluid formations according to ultrasound data in the study group at 1 week after surgery was $6.3 \pm 3.8 \mathrm{~mm}$; in the comparison group at 1 week of the post-operative period $16 \pm 12 \mathrm{~mm}$, at 1 month $9.5 \pm 5.5$, and at 3 months $8.0 \pm 1.5 \mathrm{~mm}$. In the $1^{\text {st }}$ week after surgery, these values had a statistically significant difference between the groups with $p<0.05$.

\section{The presence/absence/severity of inflammatory infiltrate}

Afterhernioplasty with mesh partially absorbable Ultra Pro implant for 1 week of the postoperative period, the patients had a mild inflammatory tissue reaction in the form of "an implantation zone" in response to mesh prosthesis installation with $6.5 \pm 3.0 \mathrm{~mm}$ of high with a hypoechoic rim of $1.4 \pm 0.5 \mathrm{~mm}$ (Figure 5). The inflammatory infiltrate in the group using mesh implant resolved by the $1^{\text {st }}$ month after surgery. In the group using modified autoplasty, an inflammatory reaction was not detected.

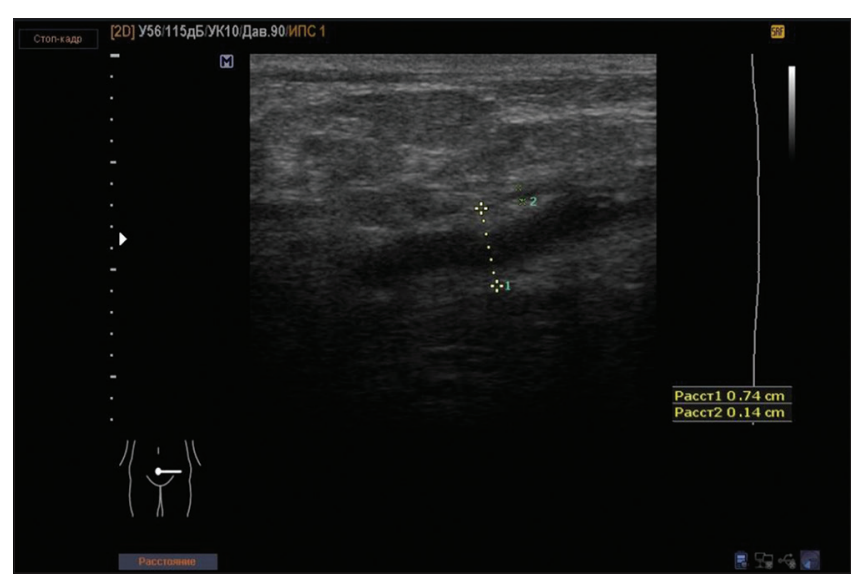

Figure 5: Inflammatory tissue reaction in the form of "an implantation zone" in response to mesh prosthesis installation in the comparison group

Tissues density (compression elastography of the post-operative area)

Ultrasound compression of the postoperative area was performed after 6 months the operation, an elastogram was created using the elasticity index (EI) to assess the soft-tissue stiffness of the changed area and surrounding tissues. The average El value of the post-operative zone in the main group was 3.0, in the comparison group - 4.6, which had statistically significant differences at $p=0.00$ according to the Mann-Whitney criterion. Intragroup tissue density data according to the Kruskal-Wallis criterion also differed statistically significantly at $p=0.00$. The surrounding tissues of the unchanged area did not statistically differ in both groups, the average $\mathrm{El}$ in the main group was 1.5 , in the comparison group -1.66 .

\section{Abdominal CT}

The tissue density was evaluated on the Hounsfield scale in 1 week and 6 months of the postoperative period (Table 1).

Table 1: Tissue density at different times after surgery according to $\mathrm{CT}$ data

\begin{tabular}{cll}
\hline Value & Modified autoplasty with a displaced aponeurotic flap & Lichtenstein hernioplasty \\
\hline 1 week & & -8.8 \\
$\bar{X}$ & 20.6 & -55 \\
Min & -6 & 6 \\
Max & 54 & 18.7 \\
SD & 15.8 & \\
6 months & 141.5 \\
$\bar{X}$ & 66.5 & 65 \\
Min & 38 & 535 \\
Max & 100 & 120.4 \\
SD & 15.7 & \\
\hline
\end{tabular}

The average values in the main group for 1 week of post-operative period were 20.6; in 6 months after surgery - 66.5, intragroup statistically significant differences were not detected. However, these data significantly differed in the comparison group $(p>0.05)$, the average values by 1 week after surgery were -8.8 , by the $6^{\text {th }}$ month -141.5 . 
Intergroup statistically significant differences were observed in the main group at $p>0.05$ and in the comparison group at $p>0.05$, according to the MannWhitney test in 1 week and 6 months after surgery. According to $\mathrm{CT}$, in the late stages of the post-operative period, an increase in tissue density was observed, most expressed in the group using mesh endoprosthesis, up to the formation of dense fibrous cords and dense scar tissue (Figure 6 demonstrates an example).

\section{Life quality after hernioplasty}

Table 2 presents the symptoms of concern from 2 to 5 points. Symptomatic pain occurred in $63.3 \%$ by the $1^{\text {st }}$ month and decreased to $20 \%$ by the $6^{\text {th }}$ month after surgery in the group using the modified autoplasty method; implant sensation - from $40 \%$ to $10 \%$; and symptom of movement restriction had the smallest values - from $40 \%$ to $0 \%$. In the comparison group, symptomatic pain was manifested in fewer patients $(23.3 \%)$, increased by the $6^{\text {th }}$ month to $46.7 \%$. Furthermore, in the group using an endoprosthesis, the activity limitation and the $\mathrm{MEsH}$ sensation from the $1^{\text {st }}$ month to the $6^{\text {th }}$ month after surgery decreased from $16.7 \%$ to $10 \%$.

\section{Discussion}

Primary unilateral inguinal hernias account for $75 \%$ hernias of the abdominal wall, at which the risk of relapse is $27 \%$ among men and $3 \%$ - among women [13]. The doctors are constantly looking for the ways to improve the surgical results of treatment

in almost all areas of medicine. Evidence-based safety and efficacy data lags far behind implant deployment rates in hernioplasty. "An ideal" implant has not yet been found, because it must meet all the necessary requirements that contribute to improving the integration of the endoprosthesis in the body.

The use of a flap of combined aponeurosis of the internal oblique and transverse abdominal muscles (which strengthens the posterior wall of the inguinal canal) was established as a new concept of the method. The modified autoplasty method is new and differs from historical methods, corresponds to the new principles of "no tension."

Most patients complain of pain after surgery due to irritation and inflammation caused by the implant in $0.7-28.7 \%$ cases [14], compared to other authors - in $28.7-43.3 \%$ of cases [15]. Other studies have confirmed that almost $30 \%$ of patients experienced pain of varying degrees even 1 year after Lichtenstein hernioplasty [16], [17]. We registered the symptomatic pain in $1 / 3$ of the patients, which persisted for 1-3 months after surgery in the group

Table 2: Comparative characteristics of the life quality parameters of the patients in the post-operative period. * Indicates a statistically significant difference; P, 05 . NS - not statistically significant (no statistically significant difference)

\begin{tabular}{|c|c|c|c|}
\hline \% Symptomatic & $\begin{array}{l}\text { Modified autoplasty with a } \\
\text { displaced aponeurotic flap } \\
\mathrm{n}=30\end{array}$ & $\begin{array}{l}\text { Lichtenstein } \\
\text { hernioplasty } \\
\mathrm{n}=30\end{array}$ & $p$-value ${ }^{*}$ \\
\hline \multicolumn{4}{|l|}{ Pain } \\
\hline 1 month & $63.3(n=16)$ & $23.3(n=7)$ & 0.02 \\
\hline 3 months & $26.7(\mathrm{n}=8)$ & $23.3(\mathrm{n}=7)$ & NS \\
\hline 6 months & $20(n=6)$ & $46.7(n=14)$ & 0.01 \\
\hline \multicolumn{4}{|l|}{ Activity limitation } \\
\hline 1 month & $40(n=12)$ & $16.7(n=5)$ & 0.04 \\
\hline 3 months & $20(n=6)$ & $26.7(\mathrm{n}=8)$ & NS \\
\hline 6 months & 0 & 0 & NS \\
\hline \multicolumn{4}{|l|}{ Mesh sensation } \\
\hline 1 month & $33.3(n=10)$ & $16.7(n=5)$ & 0.03 \\
\hline 3 months & 0 & $20(n=6)$ & NS \\
\hline 6 months & $10(n=3)$ & $10(n=7)$ & 0.03 \\
\hline
\end{tabular}

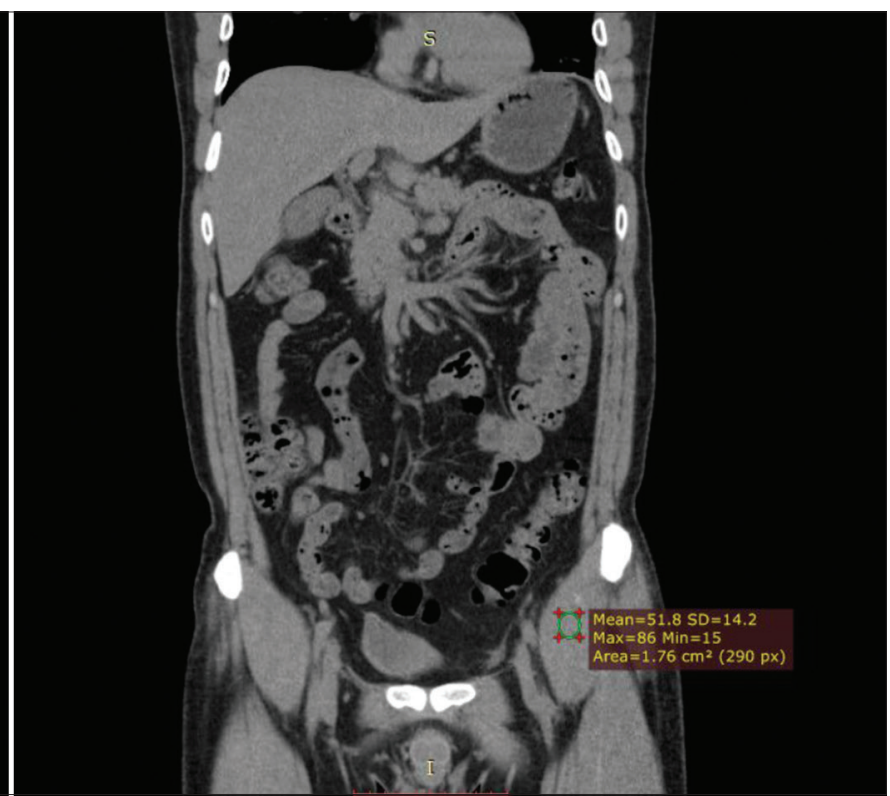

Figure 6: Computed tomography of the inguinal area, 6 months after surgery. The comparison group is on the left, the study group is on the right 
using the Lichtenstein method, persisted up to $40 \%$ after 6 months. Nevertheless, pain in the study group was expressed in the first 1 and 3 months with a statistically significant difference.

Based on the questionnaire data, it was noted that the life quality is best in the group using a mesh endoprosthesis in the early stages after surgery. Perhaps, the presence of an unexpressed inflammatory process and subclinical seromas, which were more expressed in this group, did not affect the life quality of the patients.

It is believed that cicatricial changes cause pain and discomfort in the post-operative area when using mesh implants [18], [19]. Moreover, we assume that for this reason the pain in the comparison group increased up to $46.7 \%$ to the $6^{\text {th }}$ month after surgery, and the pain decreased to $20 \%$ in the study group; in the group using the endoprosthesis, the $\mathrm{MEsH}$ sensation increased from $1^{\text {st }}$ to the $3^{\text {rd }}$ months from $16.7 \%$ to $20 \%$. This is also confirmed by CT and compression elastography, which revealed high tissue density in the postoperative zone with a statistically significant difference between the studied groups.
An analysis of the results revealed significantly higher total health indicators in patients after hernioplasty using the developed method in the late stages of the post-operative period. All symptomatic sensations and complaints in both groups (with the exception of pain in the comparison group, and statistically significant differences $>0.05$ ) decreased to the $6^{\text {th }}$ month after hernioplasty. Figure 7 demonstrates graphical representation of the data on the main three domains of life quality.

The developed method of strengthening ща the inguinal canal posterior wall has differences from analogs. It is based on the principle of "non-tension" autoplasty of the abdominal wall, which is one of the main tenets of modern herniology. The use of autoplasty has great potential in the surgical correction of inguinal hernias, as this can eliminate all the complications associated with the use of synthetic material. The main negative points of mesh endoprostheses using, based on our research results, are the formation of inflammatory infiltrate, seromas, increased tissue density and dense scars, and post-operative pain.

The formation of inflammatory infiltrate and subclinical seromas did not worsen the quality of life

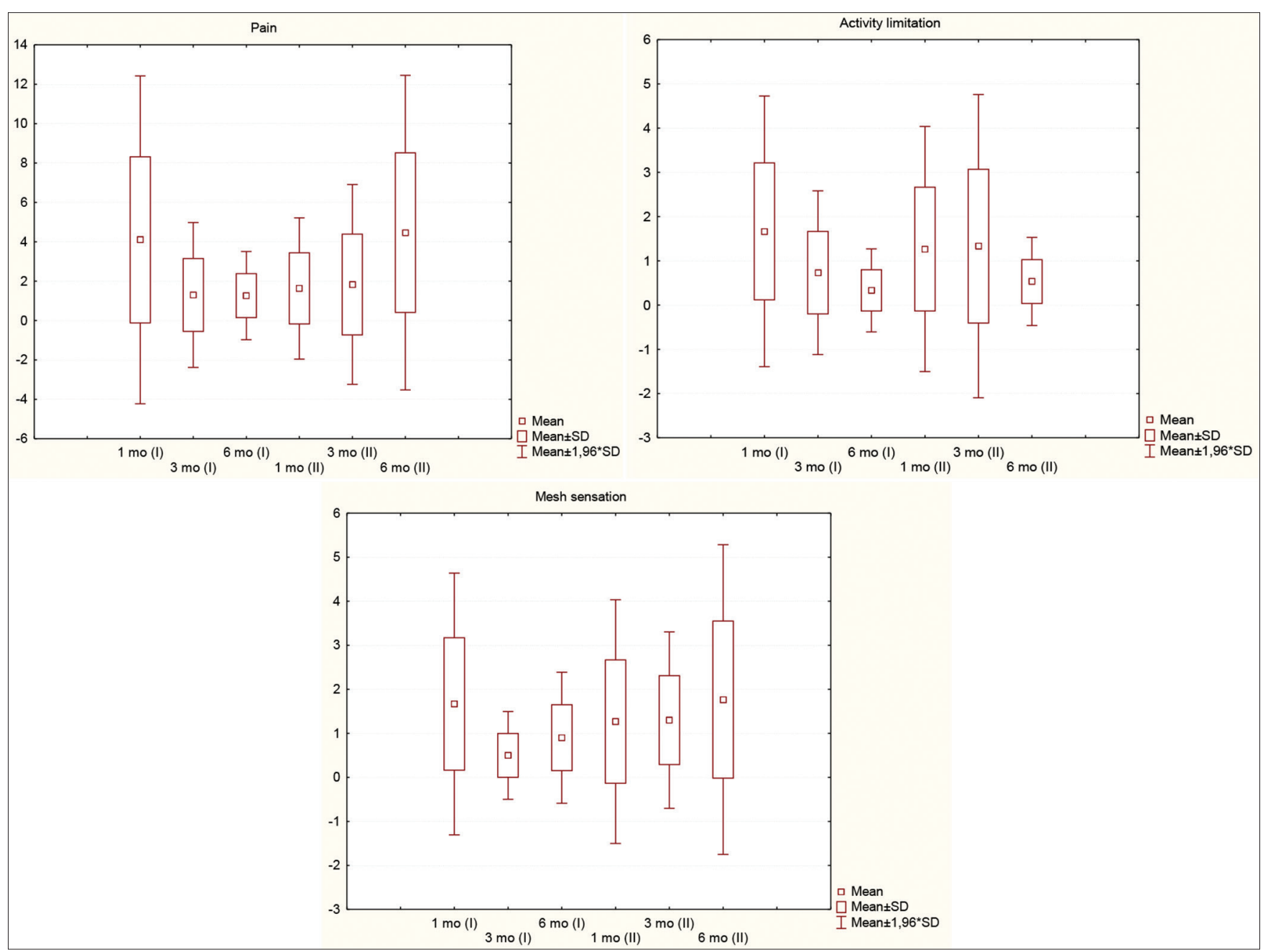

Figure 7: Boxplots postoperative quality of life as measured by the "Questionnaire for assessment of life quality of the patients after hernia repair." Quality-of-life domain by follow-up period. Group I - Autoplasty by displaced aponeurotic flap, Group II - Lichtenstein hernioplasty. $X$-axis is percent symptomatic, Y-axis terms after surgery 
in the comparison group in the early stages, but still the developed method of hernioplasty for inguinal hernias shows the better total indicators quality of life in the long-term postoperative period according to the questionnaire. Autoplasty is a reliable alternative and can compete with prosthetic methods, although the Lichtenstein method remains "the gold standard."

\section{References}

1. Simons MP, Smietanski M, Bonjer HJ, Bittner R, Miserez M, Aufenacker ThJ, et al. International guidelines for groin hernia management. Hernia. 2018;22(1):1-165. https://doi. org/10.1007/s10029-018-1729-9

PMid:29330835

2. Donati M, Brancato G, Giglio A, Biondi A, Basile F, Donati A Incidence of pain after inguinal hernia repair in the elderly. A retrospective historical cohort evaluation of 18-years' experience with a mesh and plug inguinal hernia repair method on about 3000 patients. BMC Surg. 2013;13(Suppl 2):S19. https://doi. org/10.1186/1471-2482-13-s2-s19

PMid:24268023

3. Desarda MP. Physiological repair of inguinal hernia: A new technique (study of 860 patients). Hernia. 2006;10(2):143-6. https://doi.org/10.1007/s10029-005-0039-1

PMid:16341627

4. Naveen N, Srinath R. A comparative study between modified Bassini's repair and Lichtenstein mesh repair (LMR) of inguinal hernias in rural population. J Clin Diagn Res. 2014;8(2):88-91. https://doi.org/10.7860/jcdr/2016/15368.7292 PMid:24701491

5. Harjai MM, Nagpal BM, Singh P, Singh Y. A prospective randomized controlled study of Lichtenstein's tension free versus modified bassini repair in the management of groin hernias. Med J Armed Forces India. 2007;63(1):40-3. https:// doi.org/10.1016/s0377-1237(07)80106-7

PMid:27407936

6. Di Vita G, Patti R, Barrera T, Arcoleo F. Impact of heavy polypropylene mesh and composite light polypropylene and polyglactin 910 on the inflammatory response. Surg Innov. 2010;17:229-35. https://doi.org/10.1177/1553350610371334 PMid:20798094

7. Degovtsov EN, Kolyadko PV. Seromas as a complication of surgical treatment of incisional hernias of anterior abdominal wall using mesh implants: Current state of the problem. Novosti Khirurgii. 2018;26(1):96-102. https://doi. org/10.18484/2305-0047.2018.1.96

8. Badyrov R, Abatov N, Tussupbekova M, Alberton J,
Abudaliev K. A comparative morpholopogy of anterior abdominal wall tissues after using bovine-derived peritoneum implant and acellular dermal matrix in the experiment. Eur $\mathrm{J}$ Pathopol. 2016;469(Suppl 1):S1-346. https://doi.org/10.26226/ morressier.578f37fcd462b8028d8906cb

9. Badyrov RM, Abatov NT, Tussupbekova MM, Alberton JN, Musabekov IK. Estimation of structural changes of the implantation area after application of the extracellular bovinederived peritoneum matrix for abdominal wall reconstruction in the experiment. Med Ecol. 2017;4:78-85.

10. Venditti D, Rossi P, Lisi G, De Sanctis F, Sena G, De Majo A, et al. A new prosthesis in inguinal hernia repair: Results of a pilot study. Surg Res Open J. 2015;2(2):66-71.

11. Ergül Z, Akinci M, Yilmaz KB, Sahin A, Seker G, Kulaçoğlu H. Why do we use drains in some inguinal hernia repairs? Chirurgia. 2011;106:769-74.

PMid:22308915

12. Sigrist RMS, Liau J, Kaffas AE, Chammas MC, Willmann JK Review ultrasound elastography: Review of techniques and clinical applications. The Ranostics. 2017;7(5):1303-29. https:// doi.org/10.7150/thno.18650 PMid:28435467

13. Jenkins JT, O'Dwyer PJ. Inguinal hernias. BMJ. 2008;336(7638):269-72. https://doi.org/10.1136/ bmj.39450.428275.ad PMid:18244999

14. Van Hanswijck de J, Lloyd A. Chronic pain after inguinal hernia repair. J Evol Med Dent Sci 2014;3(46):11217-26. https://doi org/10.14260/jemds/2014/3463

15. Abd Al-Fatah M, Al-Sheemy G, Abd Al-Aal A, El-Hossainy AF. Desarda inguinal herniorrhaphy. J Am Sci. 2016;12(1):132-40.

16. Bay-Nielsen M, Perkins FM, Kehlet H; Danish Hernia Database. For the Danish hernia database. Pain and functional impairment 1 year after inguinal herniorrhaphy: A nationwide questionnaire study. Ann Surg. 2001;233(1):1-7. https://doi. org/10.1097/00000658-200101000-00001 PMid:11141218

17. Oprea V, Grad O, Gheorghescu D, Moga D. Transinguinal preperitoneal mesh plasty an alternative or a dispensable technique? A prospective analyze vs lichtenstein repair for complex unilateral groin hernias. Chirurgia. 2019;114(1):48-56. https://doi.org/10.21614/chirurgia.114.1.48 PMid:30830844

18. Li J, Ji Z, Cheng T Lightweight versus heavyweight in inguina hernia repair: A meta-analysis. Hernia. 2012;16(5):529-39. https://doi.org/10.1007/s10029-012-0928-z PMid:22689249

19. Yang S, Shen YM, Wang MG, Zou ZY, Jin CH, Chen J. Titanium-coated mesh versus standard polypropylene mesh in laparoscopic inguinal hernia repair: A prospective, randomized, controlled clinical trial. Hernia. 2019;23(2):255-9. https://doi. org/10.1007/s10029-018-1823-z

PMid:30259252 